\title{
PROGRESSIVE FIBROSING INTERSTITIAL LUNG DISEASE ASSOCIATED WITH AUTOIMMUNE RHEUMATIC DISEASES: A SNAPSHOT FROM BRAZIL
}

Cristiane Kayser ${ }^{1, *}$, Carlos Alberto Pereira ${ }^{1}$, Carolina de Souza Müller ${ }^{2}$, Percival Degrava Sampaio-Barros ${ }^{3}$, Rina Dalva Neubarth Giorgi $^{4}$, Adalberto Sperb Rubin ${ }^{5,6}$, Claudia Henrique da Costa ${ }^{7}$, Karin Mueller Storrer ${ }^{8}$, Milena Cristina Vita ${ }^{9}$, Daniela Morais de Hollanda Padilha ${ }^{9}$

1. Universidade Federal de São Paulo, São Paulo (SP), Brazil. 2. Universidade Federal do Paraná, Curitiba (PR), Brazil. 3. Universidade de São Paulo, São Paulo (SP), Brazil. 4. Hospital do Servidor Público Estadual de São Paulo, São Paulo (SP), Brazil. 5. Irmandade Santa Casa de Misericórdia de Porto Alegre, Porto Alegre (RS), Brazil. 6. Universidade Federal de Ciências da Saúde de Porto Alegre, Porto Alegre (RS), Brazil. 7. Universidade Estadual do Rio de Janeiro, Rio de Janeiro (RJ), Brazil. 8. Pontífica Universidade Católica do Paraná, Curitiba (PR), Brazil. 9. Boehringer Ingelheim do Brasil Química e Farmacêutica LTDA, São Paulo (SP), Brazil.

*Corresponding author: cristiane.kayser@unifesp.br

\section{BACKGROUND}

Interstitial lung disease (ILD) is a common manifestation of autoimmune rheumatic diseases (ARD) and a leading cause of death among these patients ${ }^{1}$. A proportion of patients with ARD associated-ILDs (ARD-ILDs) will develop a progressive fibrosing ILD (PF-ILD), characterized by increasing fibrosis on high-resolution computed tomography (HRCT), worsening of lung function, and early mortality². In light of scarce data about the disease in Brazil, we performed a physician survey to explore characteristics of Brazilian PF-ILD patients.

\section{MATERIALS AND METHODS}

Forty rheumatologists and forty pulmonologists from Brazil who had managed $>10$ non-idiopathic pulmonary fibrosis patients in the past 12 months, and with $>5$ and $<35$ years of practice were invited to participate in an online interview.

\section{RESULTS}

The survey was conducted from December 2019 to January 2020. The participating physicians had an average of 14 years of experience and $7 \%$ worked in reference centers. Rheumatologists estimated that ILD developed in $12 \%$ of patients with rheumatoid arthritis (RA) and $48 \%$ with systemic sclerosis (SSc) compared to $17 \%$ of patients with other connective tissue diseases. Interestingly, pulmonologists pointed only $8 \%$ of their patients as having SSc. Both specialties estimated that at least $41 \%$ of patients with ARD-ILDs develop PF-ILD (Fig. 1). High-resolution computed tomography is the commonest test used to diagnose PF-ILD, mentioned by $100 \%$ of physicians, followed by pulmonary function tests (PFTs), used by $85 \%$ of rheumatologists and $88 \%$ of pulmonologists. On average, patients are seen every 3 months, HRCT is performed every 10 months and PFTs every 7 months. However, pulmonologists perform PFTs every 4.8 months and rheumatologists every 8.3 months, on average. Physicians estimated that, among all ARD-ILDs, patients take 1 year to be diagnosed and those with systemic sclerosis associated-ILD (SSc-ILD) have the fastest evolution, taking 72 months from symptoms to death, while rheumatoid arthritis associated-ILD (RA-ILD) takes 97 months and other connective tissue diseases associated-ILD (other CTD-ILDs) 95 months.

\section{CONCLUSION}

Brazilian physicians who manage patients with ARD-ILDs estimate that about half of the patients develop a progressive fibrosing phenotype. Pulmonary function tests and HRCT are the most common tests to diagnose and to follow up these patients. The survey indicated that SSC-ILD has the higher progression rates to death compare with all others ARD-ILD patients. 


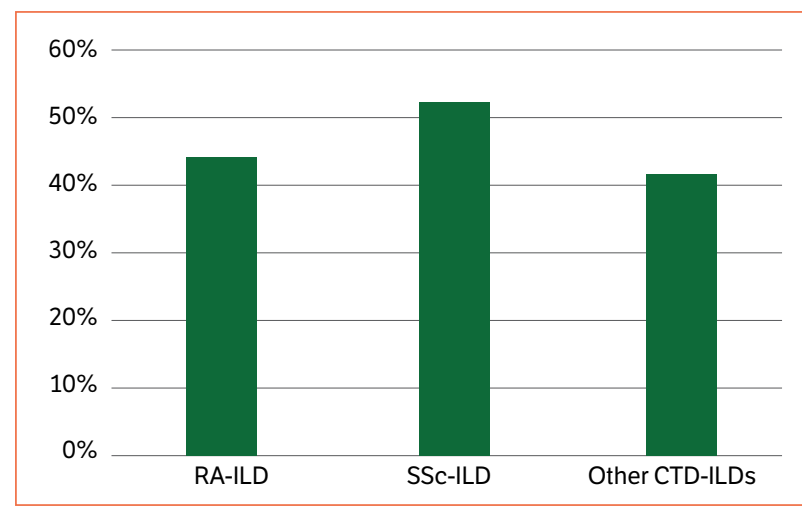

Figure 1. Estimate percentage of patients with AR-ILDs that develop PF-ILD.

\section{FUNDING}

This abstract is funded by Boehringer Ingelheim do Brasil Química e Farmacêutica Ltda.

\section{REFERENCES}

1. Kolb M, Vašáková M. The natural history of progressive fibrosing interstitial lung diseases. Respir Res. 2019;20(1):57.

2. Maher TM, Wuyts W. Management of Fibrosing Interstitial Lung Diseases. Adv Ther. 2019;36(7):1518-31. 